\title{
Rents in the era of resource scarcity: global payment flows under alternative scenarios
}

\author{
Faye Duchin $^{1 *}$ and Stephen H. Levine ${ }^{2}$
}

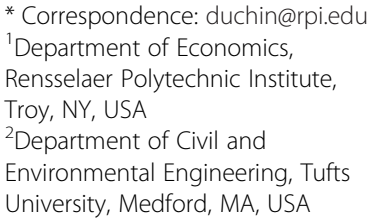

* Correspondence: duchin@rpi.edu 'Department of Economics, Rensselaer Polytechnic Institute, Troy, NY, USA

${ }^{2}$ Department of Civil and Environmental Engineering, Tufts University, Medford, MA, USA

\begin{abstract}
Resource prices rise when more costly sources need to be exploited. When the world price increases, owners of low-cost sources receive scarcity rents. The magnitude of the rents depends on the range of resource qualities being simultaneously exploited and can represent a substantial transfer of wealth to those with property rights to large stocks of high-quality, easily accessible resources. These rents are bound to increase in the future along with the size of the human population, raised consumption expectations, and deployment of technologies that depend on a wider range of natural resources for their unique properties.

We report results for a set of scenarios for a three-region, four-sector, three-resource world economy, where progressively increased consumer demand requires a second and then a third region to extract ore. This numerical example illustrates how the amount of rents transferred to the low-cost producers depends on the size of the low-cost endowments relative to world demand and on the differential costs of extraction relative to the highest-cost producer.

The paper develops a framework for tracing global money flows from payments for specific consumer goods in one or more economies to receipts by owners of the embodied factors of production under alternative scenarios about the future. This objective requires a substantial generalization of methods utilized for ex post analysis of input-output databases for past years. For a world economy of $m$ regions, $n$ sectors, and $k$ factors of production, we first compute scenario results using the World Trade Model with Bilateral Trade, then generate the Multiregional Input-Output database corresponding to each scenario, and finally compute a new Consumer-to-Factor Matrix from which the payment network is derived.
\end{abstract}

JEL Classification: F18, 013, C67, C61

Keywords: Resource scarcity; Scarcity rents; Global payment network; Global supply chain; Scenario analysis; World Trade Model with Bilateral Trade (WTMBT); Multiregional Input-Output (MRIO) database

"Growing populations, growing affluence, and the materials diversity of modern technologies are straining the resource capacities on which we draw. The situation need not inspire panic, but should instead stimulate more diligent and more comprehensive approaches to thebalance between supply and demand across the entire periodic table."

Tom Graedel et al., On the Materials Basis of Modern Society

\section{Springer}

(c) 2015 Duchin and Levine. This is an Open Access article distributed under the terms of the Creative Commons Attribution License (http://creativecommons.org/licenses/by/4.0), which permits unrestricted use, distribution, and reproduction in any medium, provided the original work is properly credited. 


\section{Background}

At a time when global demand for oil was low and supply continues to increase, Saudi Arabia announced at the November 2014 meeting of OPEC that it would not cut its production volume. This is a momentous decision on the part of the country that has been the world's largest producer and exporter of petroleum, and also, as the lowest-cost producer, the major recipient of resource rents, a country that, at other times, has cut back production to bolster prices. The ability of Saudi Arabia, and indeed of OPEC, to govern oil prices is weakened as new sources of oil and new substitutes become available, and temporarily low prices undermine this competition. Oil monopolizes our attention now, but other resources also have the potential to dramatically influence the future international distribution of income and wealth.

The key variables in determining the distribution of future resource rents include the demand for resource-intensive goods and services associated with increases in population and affluence and with changes in consumption preferences. Also important is the potential for substitutions in production among individual materials, waste management practices and secondary sources of materials, and new technologies more generally. Resource availability depends on the distribution of natural endowments, resource depletion or contamination as in the case of water, and new discoveries. Limits on production may be imposed as business strategy or due to inadequate production capacity or to legislation like environmentally motivated constraints on water withdrawals. Candidates for supply shortages include phosphate ore for fertilizer and geographically concentrated metals such as strontium (China), the platinum group (South Africa and Russia), niobium (Brazil), tellurium (United States and Australia), and manganese (Ukraine and South Africa) (Graedel et al. 2013).

Material flows in an economy start from resources, which are extracted, processed, incorporated in intermediate goods, and eventually embodied in consumer products. The supply chain for a particular consumer product includes the resources and intermediate goods required for its production. Money payments flow in the reverse direction to the material flows; they originate in the payments made by consumers for final products, continue downstream through payments for intermediate products, and terminate in payments to the owners of the embodied resources and of other factors of production, namely labor and built capital. Quantification of a payment network permits tracing the money paid for food by consumers in the United States, for example, to its ultimate recipients: the owners of built capital (in the form of profits) and workers in food processing and transport and other industries in the United States and other countries, and the farmers, and those with ownership rights to land and water in the places where the crops were grown and livestock raised. In an era of resource constraints, global transfer of rents on scarce resources can be expected to grow as a share of the prices of food, or an iPhone, and many other products. For this reason, they become increasingly critical to identify and quantify as a basis for developing resource strategies.

\subsection{Characterizing supply chains}

Porter (1985) identified the central importance for a firm of managing what he called its supply chain as a basis for creating competitive advantages. Gereffi and Korzeniewicz broadened the focus from business strategy and emphasized the payments to factors of production at each node along a product's increasingly fragmented global supply chain 
(Gereffi and Korzeniewicz 1994). Gereffi and Lee (2012) point out the value of the concept not only for business planning but also for evaluating national competitiveness and formulating development strategies. Kaplinsky and Morris stress the importance for developing countries of studying global value chains to identify opportunities to participate in the global economy on more favorable terms than just exporting raw materials (Kaplinsky and Morris, 2001). The global value chain literature includes numerous case studies, both for hightechnology sectors such as Dedrick et al. (2010) on the iPod and for processing of primary products of interest to developing countries, for example, Humphrey and Memedovic (2006) on agriculture and food or Palpacuer et al. (2005) on clothing.

Quantifying the networks requires not only data but also analysis as the chain or network structure is not directly measurable. With the recent availability of detailed input-output tables covering a large part if not the totality of the world economy, it is now possible to quantify global value chains. Timmer et al. (2014), as members of the team that compiled one of these databases (Dietzenbacher et al. 2013), use it to calculate for selected final bills of goods the corresponding payments made for 14 manufactured products in 40 countries for each year between 1995 and 2008 to three categories of workers and to owners of capital in different regions. They report, for example, that for cars sold in Germany, the portion of the value of sales that remains in Germany as payments to labor and capital has fallen from 78 to $66 \%$; while the share earned by German capital has remained unchanged at around $20 \%$, the share paid to German workers fell from 57 to $46 \%$. Labor income as a share of total value added decreased in both high-income and low-income economies, falling globally from 59 to $53 \%$. Their concerns are distinguishing value added retained in the home region or "leaked" abroad over the time period studied.

The long-established fact that a well-defined input-output computation can quantify the factors of production embodied in a given bill of final goods makes it the method of choice for computing value networks. The growing availability of detailed and documented global Multiregional Input-Output (MRIO) databases facilitates a more elaborated research program that distinguishes scarcity rents from other factor payments.

\subsection{This study}

The present study is distinctive in that we focus the analysis not on data for the past but on scenarios about the future, and we take as the general case that resources and goods are measured in physical units that may also have a unit price. We disaggregate factor endowments to distinguish built capital from natural resources: this disaggregation makes it possible to distinguish not only their physical quantities but also their factor earnings. We further distinguish the ex ante resource price, which is earned whether or not a resource endowment is fully utilized, from the scarcity rent, which is non-zero only if the constraint is binding: the sum of the two is the unit price of the resource. The paper includes a numerical example that illustrates the nature of the investigation and the kinds of conclusions that can be drawn from the analysis.

We distinguish the supply network of material inputs, both intermediate goods and resources, from the value network, which consists of payments in money values, by measuring flows in both units. When considering all the flows in the economy, the two networks have the same nodes and the same structure of arcs joining the nodes: when starting from the resources, the flows represent quantities directed toward the consumer; in the other direction, each arc is quantified as a money payment instead. However, we are interested not in the network as a whole but in sub-networks that are specific to the 
question being addressed. Government officials, or others with property rights to particular resources in one region, may want to understand in which sectoral products those resources are embodied and in which regions the production and ultimate consumption take place. Alternatively, final users or other decision makers in a region may wish to know in whose hands consumers' money outlays for particular final goods end up. Answers to these questions correspond to different sub-networks, and these sub-networks are the focus of this paper. We call attention in particular to rents earned on embodied scarce resources and the considerations that determine their magnitudes and destinations.

The scenario analysis portion of this agenda requires a model capable of capturing the impacts of scenario assumptions and a database for representing the scenarios. We make use of the World Trade Model with Bilateral Trade (WTMBT) (Strømman and Duchin 2006). The WTMBT allows for a choice among technologies in each region and assigns production of each output according to regional comparative advantages subject to factor constraints, where the factor endowments may increase or be depleted according to the scenario. Scarcity rents are earned on fully utilized, high-quality factors of production, or on technologies that are low-cost relative to others in use.

The outcomes for each scenario are then compiled, along with the exogenous scenario data, in the form of an MRIO table. The study presented here builds on the work of Duchin et al. (2015) and Duchin and Levine (2015), which describe the integration of the WTMBT scenario results about products and embodied resources into an MRIO data framework: here, that work is complemented by a focus on prices and payments. From the MRIO database for each scenario, we proceed to calculate what we call the Consumer-to-Factor Matrix (CFM), which transforms a vector containing payments of consumers in one or more regions for specific final goods to the vector of receipts by the owners of diverse factors of production in the same and other regions.

In Section 2, we first describe the quantification of payment flows in a single region utilizing the notation of the basic input-output model. The primal and dual models provide the quantities and prices, respectively. From them, we develop the CFM, which in this simple case is familiar as the matrix of total factor requirements per unit of final deliveries. We proceed to the global, multiregional system. We describe the WTMBT, and the MRIO data objects, and extend the definition of the CFM matrices from the single region to accommodate model outcomes for alternative scenarios in the case of multiple regions, as represented by the MRIO matrices.

Section 3 reports the outcomes for four alternative scenarios designed to reveal some of the key considerations in the determination of resource rents and to demonstrate the ability of the proposed framework to do so. The illustrative example is for a three-region economy with four sectors and three factors of production. As world demand grows under subsequent scenarios, the distribution of income by factor and by region shifts to reflect resource scarcities. Section 4 relates these results to the further development of this research program for addressing strategic questions about resources from the points of view of stakeholders with different interests.

The paper includes four appendices. Appendix 1 shows the algebra for the WTMBT, and Appendix 2 provides the numerical values for the WTMBT database and for the solution variables for the four scenarios. Appendix 3 shows the transformation of these data to MRIO matrices needed for deriving the CFMs and from them, the distribution of factor payments. Appendix 4 shows the numerical values for the CFM corresponding to each scenario. 


\section{Methods}

\subsection{Payment flows in a single-region economy}

The objective of this section is to develop the equation that transforms the vector of consumer payments to the associated vector of factor payments in a single region. We begin with the familiar primary input-output equation describing quantity relationships and its associated dual-price equation. We assume that all resources and products are measured in physical units and also possess a unit price. (Unpriced resources are easily accommodated, and the unit price is 1.0 in the base year if the resource or good is measured in nominal money values.) Given the $n \times 1$ vector of consumer demand, y, and A, the $n \times n$ matrix whose columns describe the intermediate input requirements per unit of output, the familiar quantity model,

$$
\mathbf{x}=\mathbf{A x}+\mathbf{y} \text { or } \mathbf{x}=(\mathbf{I}-\mathbf{A})^{-1} \mathbf{y},
$$

solves for the outputs of goods and services, the $n \times 1$ vector $\mathbf{x}$. Given $\mathbf{F}$, the $k \times n$ coefficient matrix whose columns quantify requirements for each of $k$ resources per unit of sectoral output, the resource requirements are given by the $k \times 1$ vector $\boldsymbol{\varphi}$,

$$
\boldsymbol{\varphi}=\mathbf{F x}
$$

The dual model determines unit prices, $\mathbf{p}$, for the $n$ sectoral outputs, based on exogenously specified resource prices, $\pi$,

$$
\mathbf{p}=\mathbf{A}^{T} \mathbf{p}+\mathbf{F}^{T} \boldsymbol{\pi} \text { or } \mathbf{p}=\left(\mathbf{I}-\mathbf{A}^{T}\right)^{-1} \mathbf{F}^{T} \boldsymbol{\pi} .
$$

Alternative scenarios may specify values for changes in demand, $\mathbf{y}$; in technologies, represented by columns of $\mathbf{A}$ and $\mathbf{F}$; or in factor prices, $\pi$. Note that scenarios specifying changes in technologies will in general impact both $\mathbf{x}$ and $\mathbf{p}$ even if $\mathbf{y}$ and $\boldsymbol{\pi}$ are unchanged.

We next define the $n \times 1$ vector of consumer payments $\mathbf{y}_{\mathbf{p}}=\hat{\mathbf{p}} \mathbf{y}$ and the $k \times 1$ vector of factor receipts $\varphi_{\pi}=\hat{\boldsymbol{\pi}} \varphi$. The relationship between the two is established using Eqs. (1) and (2) and the definitions of the two variables:

$$
\begin{aligned}
\boldsymbol{\varphi}_{\boldsymbol{\pi}} & =\hat{\boldsymbol{\pi}} \boldsymbol{} \\
& =\hat{\boldsymbol{\pi}} \mathbf{F} \mathbf{x} \\
& =\hat{\boldsymbol{\pi}} \mathbf{F}(\mathbf{I}-\mathbf{A})^{-1} \mathbf{y} \\
\boldsymbol{\varphi}_{\boldsymbol{\pi}} & =\left[\hat{\boldsymbol{\pi}} \mathbf{F}(\mathbf{I}-\mathbf{A})^{-\mathbf{1}} \hat{\mathbf{p}}^{-\mathbf{1}}\right] \mathbf{y}_{\mathbf{p}} .
\end{aligned}
$$

The CFM in this simple case is the familiar $k \times n$ matrix of total factor requirements per unit of final deliveries, $\mathbf{F}(\mathbf{I}-\mathbf{A})^{\mathbf{- 1}}$, converted to money values. This conversion is achieved by pre-multiplying and post-multiplying the matrix of total factor requirements by the vectors of factor prices and the inverse of prices of goods, respectively. We denote the CFM as $\Phi$ :

$$
\boldsymbol{\Phi}=\hat{\mathbf{\pi}} \mathbf{F}(\mathbf{I}-\mathbf{A})^{-1} \hat{\mathbf{p}}^{-\mathbf{1}}
$$

which can be written in terms of its individual components as follows:

$$
\boldsymbol{\Phi}=\left[\begin{array}{lll}
\phi_{11} & \phi_{12} & \phi_{13} \\
\phi_{21} & \phi_{22} & \phi_{23}
\end{array}\right]
$$




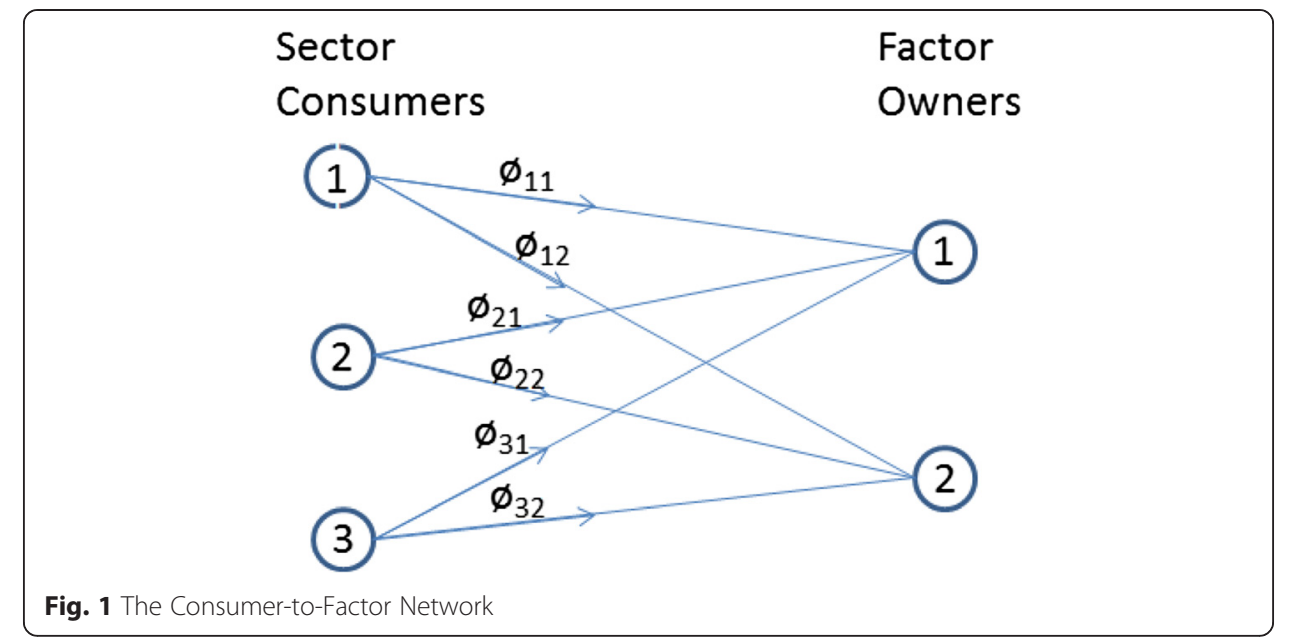

This network is illustrated in Fig. 1. Setting $B=(I-A)^{-1}$, the elements of $\Phi$ are of the form

$$
\phi_{i j}=\frac{\pi_{i}}{p_{j}}\left(\sum_{h} f_{i h} b_{h j}\right) .
$$

The components of the $j$ th column of $\Phi$ describe how each money unit, say each dollar, of consumer payments for the product of sector $j$ is ultimately distributed among the owners of the $k$ factors. The matrix $\boldsymbol{\Phi}$ is scenario-specific as the numerical values depend both on technological assumptions in $\mathbf{A}$ and $\mathbf{F}$ and on factor prices, $\boldsymbol{\pi}$. In the case of the multiregional economy, as we will see in the numerical analysis below, the payment networks are in addition responsive to changes in final demand and to the size of factor endowments.

\subsection{Payment flows in a multiregional economy}

We will be concerned with money flows in the global economy corresponding to payments for traded goods and services. The data structure for accommodating the information describing these transactions is the MRIO table. In a previous publication, Duchin and Levine (2015) define the MRIO table corresponding to a solution of the WTMBT and show how to construct it. Appendix 1 of this paper shows the equations for the WTMBT; for more detail, see Strømman and Duchin (2006).

The World Trade Model with Bilateral Trade (WTMBT) (Strømman and Duchin 2006) is a linear program that minimizes global factor use to satisfy consumption requirements while respecting regional factor constraints. Model results are the $m n \times 1$ vectors of outputs, $\mathbf{x}$, and prices, $\mathbf{p}$ (concatenations of $m$ vectors of length $n$ ), the bilateral trade vectors, $\mathbf{e}_{\mathbf{i j}}$, and two $m k \times 1$ vectors of rents, $\mathbf{r}$, received on fully utilized factors and of quantities of factor use, $\boldsymbol{\varphi}$. The WTMBT database of inputs is combined with scenario results to derive $\mathbf{A}_{\mathbf{B}}$ and $\mathbf{Y}_{\mathbf{B}}$, matrices forming the MRIO table, which are also required for the network analysis. See Appendix 3 for the definitions and derivation of $\mathbf{A}_{\mathbf{B}}$ and $\mathbf{Y}_{\mathbf{B}}$.

The WTMBT is based on the logic of comparative advantage. It distinguishes bilateral trade flows by including the costs associated with international transportation of traded goods between any two regions as well as the world price for the goods. Along with the more familiar input-output objects, $\mathbf{A}_{\mathbf{i}}, \mathbf{F}_{\mathbf{i}}, \mathbf{y}_{\mathbf{i}}$, and $\boldsymbol{\pi}_{\mathbf{i}}$ for each region $i$, the WTMBT 
database requires information on distances between pairs of regions and the mass of each product to be transported. This is accommodated in an $n \times n$ matrix, $\mathbf{T}_{\mathbf{j i}}$, for transport between each pair of regions, $i$ and $j$. We will assume that the $n$th sector, and therefore the $n$th row of $\mathbf{T}_{\mathbf{j i}}$, quantifies the demand for international transport in ton-kilometers per unit of each good imported to region $i$ from $j$. An empirical application may include several transport rows distinguished by mode of transport.

Also required for each region is $\mathbf{f}_{\mathbf{i}}$, the $k \times 1$ vector of resource endowments, which constrain a region's production capacities. When a relatively low-cost producer runs into an endowment constraint, a higher-cost producer needs to enter the market, thus raising the world price of the good in question and allowing the lower-cost producers to earn rents on their scarce factors.

In a recent paper, Duchin and Levine (2015) construct an MRIO table for each WTMBT scenario outcome. The production portion of this table is the multiregional equivalent of the one-region matrix A; we call it the Big A matrix, denoted as the $m n \times$ $m n$ matrix $\mathbf{A}_{\mathbf{B}}$. In contrast to the one-region case, an element of $\mathbf{A}_{\mathbf{B}}$ specifies the quantity of the relevant input imported for a given sector from a particular region (with the associated transport services also accounted for if it is not domestically produced). Since bilateral trade flows are endogenous to the WTMBT, $\mathbf{A}_{\mathbf{B}}$ (unlike $\mathbf{A}$ ) is scenario-specific even if there are no changes in technologies.

The matrix $\mathbf{A}_{\mathbf{B}}$ accounts for imports of intermediate goods as well as those produced domestically. Imported and domestically produced consumer goods are represented in the $m n \times m n$ matrix $\mathbf{Y}_{\mathbf{B}}$. Each row of $\mathbf{Y}_{\mathbf{B}}$ corresponds to a specific sector in a specific region and contains the deliveries of the good produced by that sector in that region to consumers in all regions. We represent this flow as an import to the corresponding domestic sector, which in turn delivers it to the consumer. Therefore, the row has at most $n$ non-zero elements, one for each region. The components of the $m n \times 1$ vector $\mathbf{y}_{\mathbf{B}}$ are calculated as the row sums of $\mathbf{Y}_{\mathbf{B}}$. Thus, each element of $\mathbf{y}_{\mathbf{B}}$ quantifies the amount of a consumer good produced in a region independent of where it is purchased and consumed. (By contrast, a component of the standard consumption vector, $\mathbf{y}$, is the quantity of the good purchased by domestic consumers independent of where it was produced.) With $\mathbf{A}_{\mathbf{B}}$ and $\mathbf{y}_{\mathbf{B}}$ so defined, it follows that:

$$
\mathbf{x}=\left(\mathbf{I}-\mathbf{A}_{\mathbf{B}}\right)^{-1} \mathbf{y}_{\mathbf{B}},
$$

where $\mathbf{x}$ is the $m n \times 1$ vector of output. (This variable follows the standard definition of $\mathbf{x}$, being the vector of output, and thus does not require a subscript $\mathrm{B}$, which is reserved for vectors or matrices having a unique definition in the MRIO database. The price vector, $\mathbf{p}$, is also defined in the standard way).

Finally, we define three more matrices. The first is $\mathbf{Y}_{\mathbf{O D}}$ (OD for off-diagonal), formed from $\mathbf{Y}_{\mathbf{B}}$ by replacing the diagonal elements (representing domestically produced consumer goods that are also sold domestically) with zeroes; consequently, $\mathbf{Y}_{\mathbf{O D}}$ contains only the exported consumer goods. The other matrices are $\mathbf{S}_{\mathbf{B}}$ and $\mathbf{T}_{\mathbf{S}}$. The former is familiar as a requirement for building any MRIO database. Typically, it is an exogenous matrix of import shares coming from the different producing regions, but in our framework, it is an endogenous outcome of the WTMBT scenario analysis. The latter matrix, $\mathbf{T}_{\mathbf{S}}$, is an input to the WTMBT and is used to incorporate the input requirements for international transport services into the $\mathbf{A}_{\mathbf{B}}$ matrix. The matrices $\mathbf{A}_{\mathbf{B}}, \mathbf{Y}_{\mathbf{B}}, \mathbf{S}_{\mathbf{B}}, \mathbf{T}_{\mathbf{S}}$, and $\mathbf{Y}_{\mathbf{O D}}$, and the vector $\mathbf{y}_{\mathbf{B}}$, are described in Appendix 3 and, in more detail, in Duchin and Levine (2015). 
We are now ready to derive the CFM that transforms consumer payments, $\mathbf{y}_{\mathbf{p}}$ (recall that $\left.\mathbf{y}_{\mathbf{p}}=\hat{\mathbf{p}} \mathbf{y}\right)$, to the receipts of factor owners, $\boldsymbol{\varphi}_{\boldsymbol{\pi}+\mathbf{r}}$ (where $\left.\boldsymbol{\varphi}_{\boldsymbol{\pi}+\mathbf{r}}=(\hat{\boldsymbol{\pi}}+\hat{\mathbf{r}}) \boldsymbol{\varphi}\right)$, for the multiregional case. We use a logic similar to the one-region derivation, substituting first for $\boldsymbol{x}$, then for $\mathbf{y}_{\mathbf{B}}$, and finally for $\mathbf{y}$ :

$$
\begin{aligned}
\boldsymbol{\varphi}_{\boldsymbol{\pi}+\mathbf{r}} & =(\hat{\boldsymbol{\pi}}+\hat{\mathbf{r}}) \mathbf{F} \mathbf{x} \\
& =(\hat{\boldsymbol{\pi}}+\hat{\mathbf{r}}) \mathbf{F}\left(\mathbf{I}-\mathbf{A}_{\mathbf{B}}\right)^{-\mathbf{1}} \mathbf{y}_{\mathbf{B}} \\
& =(\hat{\boldsymbol{\pi}}+\hat{\mathbf{r}}) \mathbf{F}\left(\mathbf{I}-\mathbf{A}_{\mathbf{B}}\right)^{-\mathbf{1}} \mathbf{S}_{\mathbf{B}}\left(\mathbf{I}+\mathbf{T}_{\mathbf{S}}\right) \mathbf{y} \\
\boldsymbol{\varphi}_{\boldsymbol{\pi}+\mathbf{r}} & =\left[(\hat{\boldsymbol{\pi}}+\hat{\mathbf{r}}) \mathbf{F}\left(\mathbf{I}-\mathbf{A}_{\mathbf{B}}\right)^{-\mathbf{1}} \mathbf{S}_{\mathbf{B}}\left(\mathbf{I}+\mathbf{T}_{\mathbf{S}}\right) \hat{\mathbf{p}}^{-1}\right] \mathbf{y}_{\mathbf{p}}
\end{aligned}
$$

where the $k n \times m n$ matrix $\boldsymbol{\Phi}_{\mathbf{B}}$ is defined as follows:

$$
\Phi_{\mathbf{B}}=(\hat{\boldsymbol{\pi}}+\hat{\mathbf{r}}) \mathbf{F}\left(\mathbf{I}-\mathbf{A}_{\mathbf{B}}\right)^{-1} \mathbf{S}_{\mathbf{B}}\left(\mathbf{I}+\mathbf{T}_{\mathbf{S}}\right) \hat{\mathbf{p}}^{-\mathbf{1}}
$$

Equation (8) is used to determine the distribution of payments to factor owners using the CFM, defined as $\boldsymbol{\Phi}_{\mathbf{B}}$ in Eq. (9), the multiregional counterpart of Eq. (5). As in the case of Eq. (5), the column of $\boldsymbol{\Phi}_{\mathbf{B}}$ corresponding to a specific sector in a given region indicates the distribution one dollar's worth of consumer purchases of that sector's output among the owners of all factors in all regions. Thus, the CFM generalizes the one-region total factor requirements matrix in that it is the result of a scenario analysis rather than the compilation of accounting data, it is multiregional in scope, it distinguishes resources from built capital and scarcity rents from other resource costs, and it incorporates the interregional transport of imports.

Since we are especially interested in the impact of scenario assumptions on scarcity rents, we supplement Eq. (8) by the following variable defined to contain only the rent payment: $\boldsymbol{\varphi}=\hat{\mathbf{r}} \mathbf{F}\left(\mathbf{I}-\mathbf{A}_{\mathbf{B}}\right)^{-\mathbf{1}} \mathbf{S}_{\mathbf{B}}\left(\mathbf{I}+\mathbf{T}_{\mathbf{S}}\right) \hat{\mathbf{p}}^{-\mathbf{1}} \mathbf{y}_{\mathbf{p}}$. When a factor is scarce, the size of the rent will reflect the differences in quality, ease of access, or desirable geographic location of one endowment relative to others.

\section{Results and discussion}

Now, we are ready to illustrate what can be learned about the consequences of resource scarcity using the combination of the WTMBT model for scenario analysis, the MRIO data structure, and the CFM to quantify payment flows corresponding to alternative scenarios. The logic of the approach is made transparent in a sequence of illustrative scenarios. We consider a world comprised of several regions that are jointly able to fully satisfy consumption demand with the factor endowments at hand, with each region specializing according to its comparative advantage. World consumption demand grows under subsequent scenarios, with implications for prices, scarcity rents, and the division of income both over factors and geographically.

The numerical example includes three regions, four sectors, and three factors of production. The regions are stylized versions of (1) an industrialized, (2) an agricultural, and (3) a mineral-rich economy. Each has four production sectors: (1) agriculture, (2) manufacturing, (3) mining, and (4) interregional transportation services. The factors are (1) labor, (2) ore, and (3) land. The scenarios include a baseline, S0, and three alternative scenarios, S1, S2, and S3, that assume a progressive increase of 10, 20, and $30 \%$, respectively, in consumer demand for all products in the resource-rich region. Numerical 
values for the $\mathbf{A}, \mathbf{F}$, and $\mathbf{T}$ matrices and the $\mathbf{y}, \boldsymbol{\pi}$, and $\mathbf{f}$ vectors, for the baseline scenario, are given in Appendix 2, along with the numerical results for the four scenarios.

The database for the baseline scenario, S0, is constructed to allow for complete specialization, with the industrialized region producing all the manufactured goods and providing international transport services, the agricultural region growing all the food, and the resource-rich region extracting all the ore for the global economy. This outcome is assured by specifying adequate regional endowments to allow the lowest-cost producer of each good to satisfy total global demand.

The regional baseline results for output, $\mathbf{x}$, prices, $\mathbf{p}$, factor use, $\boldsymbol{\varphi}$, and scarcity rents, $\mathbf{r}$, are shown in Appendix 2. The output vector reflects the pattern of specialization. Product prices vary across regions due to the different costs of transporting imports. The prices are naturally lowest in the regions that produce for domestic consumption since international transportation of imports is not required. All regions require labor, but land is used only in agriculture and ore only in mining. Since no factors are fully utilized, rents, $\mathbf{r}$, are all zero.

Scenario S1 specifies a $10 \%$ increase in final demand in the resource-rich region. The resource-rich region can no longer satisfy total global demand for ore, so the next lower-cost region, in this case region 1, must also mine ore. Region 1 extracts 2.75 tons while region 3 uses its full endowment of 150 tons and receives a scarcity rent of $\$ 0.80$ per ton in addition to the $\$ 2.00$ per ton ( $\pi$, see Appendix 2) it received in the baseline case. The price of the output of the mining sector rises by about $25 \%$ while the other prices are much less affected. The increase in payments to the owners of ore in region 3 is almost entirely due to the emergence of a scarcity rent.

Under scenario S2, final demand in region 3 is further increased to exceed baseline consumption by $20 \%$. Naturally, outputs of all sectors increase relative to S1. Prices, however, remain unchanged from their values under S1. The reason is that the endowments in all regions are adequate to support the same regional pattern of production and trade under scenario S2 as under S1. Since the costs of the highest-cost producer, namely region 1 , have not increased, the scarcity rents are also unchanged from the previous scenario. The receipts of all factor owners increase slightly to account for the larger quantities of resources required.

With an increase in the final demand in region 3 to $30 \%$ over the baseline, sectoral outputs increase further. This time, however, there is a disproportionately large increase in prices relative to the other scenarios. The reason for this steep increase is twofold. First, region 1 has now also exhausted its endowment of ore, so an even higher-cost region, region 2, must begin to mine ore. Second, the cost structure of region 2 is substantially higher than that of region 1 , and it is the cost of the highest-cost region that actually produces that sets the world price. The rent per ton of ore in region 3 increases, but it is only slightly higher than that in region 1 since the latter is only a slightly higher-cost producer. However, both rents (at $\$ 7.32$ and $\$ 9.29$, respectively) are much higher than the price of ore under the baseline scenario of $\$ 2$ per ton in region 3.

The values of $\varphi_{\boldsymbol{\pi}+\mathbf{r}}$ obtained using Eq. (8) are shown in the first block column of Table 1, with the distribution over factors (row percentages) and across regions (column percentages) shown in the following block columns. The share of global income earned by the resource-rich region increases from $22 \%$ (22.3\% in the table) under the baseline scenario, to $28 \%$ under scenarios S1 and S2, to $57 \%$ under scenario S3. The share of 
Table 1 Earnings by factor and by region under alternative scenarios

\begin{tabular}{|c|c|c|c|c|c|c|c|c|c|c|c|c|}
\hline \multirow[b]{2}{*}{ so } & \multicolumn{4}{|l|}{ Dollars } & \multicolumn{4}{|c|}{ Percent by factor } & \multicolumn{4}{|c|}{ Percent by region } \\
\hline & Factors & & & & & & & & & & & \\
\hline Region & Labor & Ore & Land & Total & Labor & Ore & Land & Total & Labor & Ore & Land & Total \\
\hline 1 & 169.87 & 0 & 0 & 169.87 & 100.00 & 0.00 & 0.00 & 100.00 & 33.30 & 0.00 & 0.00 & 11.80 \\
\hline 2 & 315.79 & 0 & 631.58 & 947.37 & 33.30 & 0.00 & 66.70 & 100.00 & 61.90 & 0.00 & 100.00 & 65.90 \\
\hline 3 & 24.70 & 296.45 & 0 & 321.15 & 7.70 & 92.30 & 0.00 & 100.00 & 4.80 & 100.00 & 0.00 & 22.30 \\
\hline Total & 510.36 & 296.45 & 631.58 & 1438.39 & 35.50 & 20.60 & 43.90 & 100.00 & 100.00 & 100.00 & 100.00 & 100.00 \\
\hline \multicolumn{13}{|l|}{ S1 } \\
\hline Region & Labor & Ore & Land & Total & Labor & Ore & Land & Total & Labor & Ore & Land & Total \\
\hline . & 176.13 & 6.05 & 0 & 182.18 & 96.70 & 3.30 & 0.00 & 100.00 & 33.60 & 1.40 & 0.00 & 11.40 \\
\hline 2 & 322.64 & 0 & 645.28 & 967.92 & 33.30 & 0.00 & 66.70 & 100.00 & 61.60 & 0.00 & 100.00 & 60.70 \\
\hline 3 & $25: 00$ & 419.40 & 0 & 444.40 & 5.60 & 94.40 & 0.00 & 100.00 & 4.80 & 98.60 & 0 & 27.90 \\
\hline Total & 523.77 & 425.45 & 645.28 & 1594.50 & 32.80 & 26.70 & 40.50 & 100.00 & 100.00 & 100.00 & 100.00 & 100.00 \\
\hline \multicolumn{13}{|l|}{ S2 } \\
\hline Region & Labor & Ore & Land & Total & Labor & Ore & Land & Total & Labor & Ore & Land & Total \\
\hline 1 & 183.52 & 16.64 & 0 & 200.16 & 91.70 & 8.30 & 0.00 & 100.00 & 34.10 & 3.80 & 0.00 & 12.30 \\
\hline 2 & 329.51 & 0 & 659.02 & 988.53 & 33.30 & 0.00 & 66.70 & 100.00 & 61.20 & 0.00 & 100.00 & 60.50 \\
\hline 3 & 25:00 & 419.40 & 0 & 444.40 & 5.60 & 94.40 & 0.00 & 100.00 & 4.60 & 96.20 & 0.00 & 27.20 \\
\hline Total & 538.03 & 436.04 & 659.02 & 1633.09 & 32.90 & 26.70 & 40.40 & 100.00 & 100.00 & 100.00 & 100.00 & 100.00 \\
\hline \multicolumn{13}{|l|}{ S3 } \\
\hline Region & Labor & Ore & Land & Total & Labor & Ore & Land & Total & Labor & Ore & Land & Total \\
\hline 1 & 190.48 & 95.22 & 0 & 285.70 & 66.70 & 33.30 & 0.00 & 100.00 & 34.40 & 5.30 & 0.00 & 9.40 \\
\hline 2 & 337.57 & 20.63 & 673.43 & 1031.63 & 32.70 & 2.00 & 65.30 & 100.00 & 61.00 & 1.10 & 100.00 & 34.00 \\
\hline 3 & 25:00 & 1693.05 & 0 & 1718.05 & 1.50 & 98.50 & 0.00 & 100.00 & 4.50 & 93.60 & 0.00 & 56.60 \\
\hline Total & 553.05 & 1808.90 & 673.43 & 3035.38 & 18.20 & 59.60 & 22.20 & 100.00 & 100.00 & 100.00 & 100.00 & 100.00 \\
\hline
\end{tabular}

global income earned by those with property rights to ore increases from 21 to $60 \%$ of total world income, over $90 \%$ of it being received in the resource-rich, low-cost region. With this enormous transfer of wealth, the earnings of resource owners have increased considerably more steeply than prices, growing more than sixfold between S0 and S3.

\section{Conclusions}

This paper calls attention to the challenges surrounding resource scarcities that are bound to become increasingly more critical in the future as consumption demand grows and resource endowments are depleted. We present an approach for anticipating these challenges through scenario analysis supplemented by the ex post derivation of the payment networks associated with scenario outcomes. The framework can also be used to evaluate approaches to addressing the challenges through measures including resource substitution, technological substitutions, recycling, and shifts to less resourceintensive consumption patterns.

An illustrative numerical example for a three-region, four-sector, three-factor economy clearly demonstrates that increases in resource demand may have minimal, 
moderate, or very substantial impacts on prices of resource-intensive goods and on scarcity rents, depending on the global abundance and distribution of the resource relative to the volume of demand. However, an additional consideration is also decisive: the differences in qualities of resource endowments and the cost structure of the technologies for exploiting them.

One direction for empirical analysis is to explore the impacts of cartel-like behavior through scenarios imposing intentional limits on production or on exports to maintain prices high. The consequences of special treatment within trading blocks can also be examined. As we expand our use of materials to exploit the distinctive features of virtually all elements in the periodic table, the prospects for unanticipated shortages multiply. For example, lithium ion batteries now attract a lot of attention, but knowledge about the global distribution of lithium reserves in the earth's crust is still quite preliminary. Scenarios about the potential mismatch between supply and demand can examine ways to prepare for abrupt shifts in availability and prices.

Methodologically, we have developed a new object, the Consumer-to-Factor Matrix, situated within a Multiregional Input-Output framework, for mapping a vector of consumer payments for one good or an entire bill of goods in one or more regions of the world to the associated payments received by owners of all embodied factors of production in the same and other regions. Like other MRIO techniques, the CFM can be applied ex post to MRIO matrices for the past. However, we have shown in a recent set of papers the reasons why an input-output model of the world economy based on a theory of trade that makes the regional division of labor endogenous is needed for MRIO analysis of alternative scenarios and demonstrated how to compile those scenario outcomes into an MRIO table (Duchin et al. 2015; Duchin and Levine, 2015). In this paper, we put those ideas to work in an illustrative numerical analysis that clarifies some of the fundamental issues surrounding future scarcity rents when confronted with increases in demand.

The approach is readily applied to scenarios involving voluntary reductions in output of critical materials or products to raise prices by inducing ever higher-cost producers to enter the market, voluntary increases in production by low-cost producers if capacities allow in order to force out fledgling substitutes by requiring very high subsidies to keep them in business, and indeed, the choice among alternative technologies under scenarios affecting their relative cost structures. Such analyses can inform strategies for resource management for regions rich in potentially scarce materials and for those that depend on importing them. These analyses can also help establish priorities among materials that are candidates for more intensive recovery and recycling in order to avoid highly disruptive events in the global economy, namely limits in access to resourcesbesides petroleum-on which we have come to depend, or steep increases in their prices.

\section{Appendices}

\subsection{Appendix 1: The World Trade Model with Bilateral Trade (WTMBT)}

The quantity and price models of the WTMBT are given below in Eqs. (10)-(13) and (14)-(17), respectively. The quantity equations are shown first-despite the fact that we focus here on the price model-by convention since in the past, most analyses have focused on the primal problem only. 


$$
\begin{aligned}
& \text { Minimize } C=\sum_{\mathbf{i}} \boldsymbol{\pi}_{\mathbf{i}}^{T} \mathbf{F}_{\mathbf{i}} \mathbf{x}_{\mathbf{i}} \\
& \mathbf{x}_{\mathbf{i}}+\sum_{\mathbf{j} \neq \mathbf{i}} \mathbf{e}_{\mathbf{j i}}=\mathbf{A}_{\mathbf{i}} \mathbf{x}_{\mathbf{i}}+\mathbf{y}_{\mathbf{i}}+\sum_{\mathbf{j} \neq \mathbf{i}} \mathbf{e}_{\mathbf{i} \mathbf{j}}+\sum_{\mathbf{j} \neq \mathbf{i}} \mathbf{T}_{\mathbf{j i}} \mathbf{e}_{\mathbf{j} \mathbf{i}}, \forall i \\
& \mathbf{F}_{\mathbf{i}} \mathbf{x}_{\mathbf{i}} \leq \mathbf{f}_{\mathbf{i}}, \forall i \\
& \mathbf{x}_{\mathbf{i}} \geq \mathbf{0}, \forall i .
\end{aligned}
$$

The price dual takes the following form:

$$
\text { Maximize } Z=\sum_{\mathbf{i}} \mathbf{y}_{\mathbf{i}}^{T} \mathbf{p}_{\mathbf{i}}-\sum_{\mathbf{i}} \mathbf{f}_{\mathbf{i}}^{T} \mathbf{r}_{\mathbf{i}}
$$

such that

$$
\begin{aligned}
& \left(\mathbf{I}-\mathbf{A}_{\mathbf{i}}^{T}\right) \mathbf{p}_{\mathbf{i}} \leq \mathbf{F}_{\mathbf{i}}^{T}\left(\boldsymbol{\pi}_{\mathbf{i}}+\mathbf{r}_{\mathbf{i}}\right), \forall i \\
& \left(\mathbf{p}_{\mathbf{i}}-\mathbf{p}_{\mathbf{j}}\right) \leq \mathbf{T}_{\mathbf{j i}}^{T} \mathbf{p}_{\mathbf{i}}, \forall i \neq j . \\
& \mathbf{p}_{\mathbf{i}}, \mathbf{r}_{\mathbf{i}} \geq \mathbf{0}, \forall i
\end{aligned}
$$

The price of each good in the producing region is determined by Eq. (15), with the highest-cost region, among those regions that actually produce and export the good, setting the price and receiving no rent, while all lower-cost producers charge the same price and receive scarcity rents as the difference between the price and their costs. The second price constraint, Eq. (16), describes price formation in importing regions, for which a strict equality holds. (See Strømman and Duchin, 2006 for proofs.) The WTMBT accounts for the role of interregional transport sectors in providing the transport service (Eq. 11) and in determining regional prices (Eq. 16). The $\mathbf{T}_{\mathbf{j i}}$ matrices contain zeroes in all rows except the row (or rows) corresponding to the transport sectors. (The role of these matrices is illustrated in the numerical example of Section 4.) The $n$th element in each region's $n \times 1$ price vector, $\mathbf{p}_{\mathbf{i}}$, (the element corresponding to the transport sector) is the price per ton-kilometer, and the price for an imported good sold in region $i$ includes the cost of purchasing the good and of transporting it. See Strømman and Duchin (2006) for more details.

\subsection{Appendix 2. Database and results for the scenario analyses in Section 4}

This appendix contains the WTMBT database for the scenario analysis in Section 4 for the economy of three regions, four sectors, and three factors of production. The model is shown in Appendix 1.

Regions: (1) industrialized, (2) agricultural, (3) mineral-rich.

Sectors: (1) agriculture, (2) manufacturing, (3) mining, (4) interregional transportation.

Factors: (1) labor, (2) ore, (3) land). 


\subsubsection{Exogenous data}

The baseline A, F, and $\mathbf{T}$ matrices and the $\mathbf{y}, \boldsymbol{\pi}$, and $\mathbf{f}$ vectors for scenario S0 are as follows:

$\begin{aligned} \mathbf{A} & =\left[\begin{array}{cccc|cccc|cccc}0.13 & 0.08 & 0 & 0 & 0 & 0 & 0 & 0 & 0 & 0 & 0 & 0 \\ 0.25 & 0.50 & 0.35 & 0.20 & 0 & 0 & 0 & 0 & 0 & 0 & 0 & 0 \\ 0.40 & 0.30 & 0.06 & 0.50 & 0 & 0 & 0 & 0 & 0 & 0 & 0 & 0 \\ 0 & 0 & 0 & 0 & 0 & 0 & 0 & 0 & 0 & 0 & 0 & 0 \\ \hline 0 & 0 & 0 & 0 & 0.20 & 0.10 & 0 & 0 & 0 & 0 & 0 & 0 \\ 0 & 0 & 0 & 0 & 0.10 & 0.50 & 0.50 & 0.05 & 0 & 0 & 0 & 0 \\ 0 & 0 & 0 & 0 & 0.20 & 0.30 & 0.10 & 0.06 & 0 & 0 & 0 & 0 \\ 0 & 0 & 0 & 0 & 0 & 0 & 0 & 0 & 0 & 0 & 0 & 0 \\ \hline 0 & 0 & 0 & 0 & 0 & 0 & 0 & 0 & 0.30 & 0.10 & 0 & 0 \\ 0 & 0 & 0 & 0 & 0 & 0 & 0 & 0 & 0.40 & 0.50 & 0.30 & 0.30 \\ 0 & 0 & 0 & 0 & 0 & 0 & 0 & 0 & 0.50 & 0.30 & 0.05 & 0.50 \\ 0 & 0 & 0 & 0 & 0 & 0 & 0 & 0 & 0 & 0 & 0 & 0\end{array}\right] \\ \mathbf{F} & =\left[\begin{array}{cccc|cccc|cccc}1.75 & 0.50 & 0.50 & 0.20 & 0 & 0 & 0 & 0 & 0 & 0 & 0 & 0 \\ 0 & 0 & 1.80 & 0 & 0 & 0 & 0 & 0 & 0 & 0 & 0 & 0 \\ 2.00 & 0 & 0 & 0 & 0 & 0 & 0 & 0 & 0 & 0 & 0 & 0 \\ \hline 0 & 0 & 0 & 0 & 8.00 & 10.00 & 1.00 & 10.00 & 0 & 0 & 0 & 0 \\ 0 & 0 & 0 & 0 & 0 & 0 & 2.40 & 0 & 0 & 0 & 0 & 0 \\ 0 & 0 & 0 & 0 & 4.00 & 0 & 0 & 0 & 0 & 0 & 0 & 0 \\ \hline 0 & 0 & 0 & 0 & 0 & 0 & 0 & 0 & 10.00 & 10.00 & 0.25 & 15.00 \\ 0 & 0 & 0 & 0 & 0 & 0 & 0 & 0 & 0 & 0 & 1.50 & 0 \\ 0 & 0 & 0 & 0 & 0 & 0 & 0 & 0 & 5.00 & 0 & 0 & 0\end{array}\right]\end{aligned}$

$\mathbf{T}=\left[\begin{array}{cccc|cccc|cccc}0 & 0 & 0 & 0 & 0 & 0 & 0 & 0 & 0 & 0 & 0 & 0 \\ 0 & 0 & 0 & 0 & 0 & 0 & 0 & 0 & 0 & 0 & 0 & 0 \\ 0 & 0 & 0 & 0 & 0 & 0 & 0 & 0 & 0 & 0 & 0 & 0 \\ 0 & 0 & 0 & 0 & 0.050 & 0.060 & 0.055 & 0 & 0.075 & 0.090 & 0.083 & 0 \\ \hline 0 & 0 & 0 & 0 & 0 & 0 & 0 & 0 & 0 & 0 & 0 & 0 \\ 0 & 0 & 0 & 0 & 0 & 0 & 0 & 0 & 0 & 0 & 0 & 0 \\ 0 & 0 & 0 & 0 & 0 & 0 & 0 & 0 & 0 & 0 & 0 & 0 \\ 0.050 & 0.060 & 0.055 & 0 & 0 & 0 & 0 & 0 & 0.063 & 0.075 & 0.069 & 0 \\ \hline 0 & 0 & 0 & 0 & 0 & 0 & 0 & 0 & 0 & 0 & 0 & 0 \\ 0 & 0 & 0 & 0 & 0 & 0 & 0 & 0 & 0 & 0 & 0 & 0 \\ 0 & 0 & 0 & 0 & 0 & 0 & 0 & 0 & 0 & 0 & 0 & 0 \\ 0.075 & 0.090 & 0.083 & 0 & 0.063 & 0.075 & 0.069 & 0 & 0 & 0 & 0 & 0\end{array}\right]$

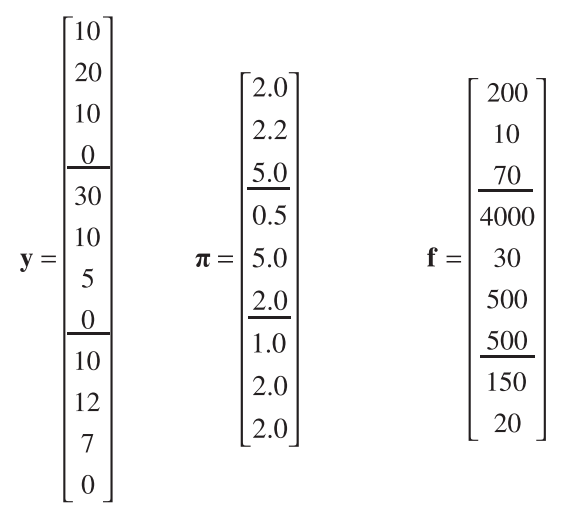

Consumer demand for all goods in the resource-rich region (the last four figures in the y vector) is increased for each subsequent scenario: by $10 \%$ under S1, $20 \%$ under S2, and 30 \% under S3. 


\subsubsection{Model solutions}

Scenario results are reported below in Table 2 for output, $\mathbf{x}$, and prices, $\mathbf{p}$, and in Table 3 for factor use, $\varphi$, and scarcity rents, $\mathbf{r}$.

Table 2

\begin{tabular}{|c|c|c|c|c|c|c|c|c|c|}
\hline \multirow[b]{2}{*}{ Region } & \multirow[b]{2}{*}{ Sector } & \multicolumn{2}{|l|}{ SO } & \multicolumn{2}{|l|}{$\mathrm{S} 1$} & \multicolumn{2}{|l|}{$\mathrm{S} 2$} & \multicolumn{2}{|l|}{ S3 } \\
\hline & & Output (x) & Prices $(p)$ & Output (x) & Prices $(p)$ & Output (x) & Prices $(p)$ & Output (x) & Prices $(p)$ \\
\hline \multirow[t]{4}{*}{1} & Agr. & 0 & 18.16 & 0 & 18.80 & 0 & 18.80 & 0 & 25.61 \\
\hline & Mfg. & 164.47 & 9.05 & 169.10 & 10.20 & 173.77 & 10.20 & 179.28 & 22.43 \\
\hline & Mining & 0 & 6.91 & 1.53 & 8.65 & 4.20 & 8.65 & 5.56 & 27.22 \\
\hline & Transport & 13.49 & 5.66 & 13.75 & 6.76 & 13.86 & 6.76 & 14.10 & 18.50 \\
\hline \multirow[t]{4}{*}{2} & Agr. & 78.95 & 17.88 & 80.66 & 18.46 & 82.38 & 18.46 & 84.18 & 24.68 \\
\hline & Mfg. & 0 & 9.39 & 0 & 10.60 & 0 & 10.60 & 0 & 22.54 \\
\hline & Mining & 0 & 6.83 & 0 & 8.56 & 0 & 8.56 & 1.72 & 26.97 \\
\hline & Transport & 0 & 5.66 & 0 & 6.76 & 0 & 6.76 & 0 & 18.50 \\
\hline \multirow[t]{4}{*}{3} & Agr. & 0 & 18.24 & 0 & 18.89 & 0 & 18.89 & 0 & 25.84 \\
\hline & Mfg. & 0 & $9 . \mathrm{V}$ & 0 & 10.81 & 0 & 10.81 & 0 & 24.10 \\
\hline & Mining & 98.82 & 6.44 & 100.00 & 8.09 & 100.00 & 8.09 & 100.00 & 25.70 \\
\hline & Transport & 0 & 5.66 & 0 & 6.76 & 0 & 6.76 & 0 & 18.50 \\
\hline
\end{tabular}

Table 3

\begin{tabular}{|c|c|c|c|c|c|c|c|c|c|}
\hline \multirow[b]{2}{*}{ Region } & \multirow[b]{2}{*}{ Factor } & \multicolumn{2}{|l|}{ so } & \multicolumn{2}{|l|}{$\mathrm{S} 1$} & \multicolumn{2}{|l|}{$\mathrm{S} 2$} & \multicolumn{2}{|l|}{ S3 } \\
\hline & & Factor use $(\phi)$ & Rents $(r)$ & Factor use $(\phi)$ & Rents (r) & Factor use $(\phi)$ & Rents $(r)$ & Factor use $(\phi)$ & Rents (r) \\
\hline \multirow[t]{3}{*}{1} & Labor & 84.93 & 0 & 88.06 & 0 & 91.76 & 0 & 95.24 & 0 \\
\hline & One & 0 & 0 & 2.75 & 0 & 7.56 & 0 & 10 & 7.32 \\
\hline & Land & 0 & 0 & 0 & 0 & 0 & 0 & 0 & 0 \\
\hline \multirow[t]{3}{*}{2} & Labor & 631.58 & 0 & 645.28 & 0 & 659.02 & 0 & 675.14 & 0 \\
\hline & One & 0 & 0 & 0 & 0 & 0 & 0 & 4.13 & 0 \\
\hline & Land & 315.79 & 0 & 322.64 & 0 & 329.51 & 0 & 336.71 & 0 \\
\hline \multirow[t]{3}{*}{3} & Labor & 24.70 & 0 & 25.00 & 0 & 25.00 & 0 & 25.00 & 0 \\
\hline & One & 148.22 & 0 & 150.00 & 0.80 & 150.00 & 0.80 & 150.00 & 9.29 \\
\hline & Land & 0 & 0 & 0 & 0 & 0 & 0 & 0 & 0 \\
\hline
\end{tabular}

5.3 Appendix 3. Creating the MRIO database from the scenario results for the Consumer-to-Factor payment calculations of Section 3

The results of a scenario run with the WTMBT are organized as an MRIO database, and the Consumer-to-Factor Matrix is derived in Section 3 from the MRIO database. In this appendix, we show how the four MRIO matrices $\mathbf{A}_{\mathbf{B}}, \mathbf{S}_{\mathbf{B}}, \mathbf{T}_{\mathbf{S}}$, and $\mathbf{Y}_{\mathbf{B}}$ (all of dimension $m n \times m n$ for $m$ regions and $n$ sectors) are derived from the WTMBT database and scenario results.

$\mathbf{A}_{\mathbf{B}}$ is the MRIO equivalent of the standard input-output coefficient matrix for intermediate products for a single region. It differs in that the former distinguishes intermediate inputs according to where they are produced via $\mathbf{S}_{\mathbf{B}}$, and the transportation of imports to the purchasing region must be incorporated via $\mathbf{T}_{\mathbf{S}}$. These adjustments can be made only after the scenarios are run, as both $\mathbf{S}_{\mathbf{B}}$ and $\mathbf{T}_{\mathbf{S}}$ are determined endogenously. These objects are defined as follows:

$$
A_{B}=S_{B}\left(I+T_{S}\right) A=S_{B} A+S_{B} T_{S} A
$$


where, for the three-region case,

$$
\begin{aligned}
\mathbf{A} & =\left[\begin{array}{ccc}
\mathbf{A}_{1} & \mathbf{0} & \mathbf{0} \\
\mathbf{0} & \mathbf{A}_{2} & \mathbf{0} \\
\mathbf{0} & \mathbf{0} & \mathbf{A}_{3}
\end{array}\right] \\
\mathbf{T}_{\mathbf{S}} & =\left[\begin{array}{ccc}
\mathbf{T}_{\mathbf{S} 1} & \mathbf{0} & \mathbf{0} \\
\mathbf{0} & \mathbf{T}_{\mathrm{S} 2} & \mathbf{0} \\
\mathbf{0} & \mathbf{0} & \mathbf{T}_{\mathrm{S} 3}
\end{array}\right] \\
\mathbf{S}_{\mathbf{B}} & =\left[\begin{array}{ccc}
\hat{\mathbf{S}}_{11} & \hat{\mathbf{S}}_{12} & \hat{\mathbf{S}}_{13} \\
\hat{\mathbf{s}}_{21} & \hat{\mathbf{S}}_{22} & \hat{\mathbf{S}}_{23} \\
\hat{\mathbf{s}}_{31} & \hat{\mathbf{S}}_{32} & \hat{\mathbf{S}}_{33}
\end{array}\right]
\end{aligned}
$$

The $\mathbf{S}_{\mathbf{B}}$ matrix consists of a block diagonal sub-matrix $\hat{\mathbf{S}}_{\mathbf{i j}}$ for each pairing of regions, nine blocks in the case of three regions, containing the proportion for each good that is imported to region $j$ from region $i$ (or domestically produced when $i=\mathrm{j}$ ) for the domestic intermediate or final use. The individual components can be defined as follows:

$$
\hat{\mathbf{S}}_{\mathbf{i j}}=\left\{\begin{array}{l}
\left(\hat{\mathbf{x}}_{\mathbf{j}}+\sum_{h \neq j} \hat{\mathbf{e}}_{\mathbf{h j}}\right)^{-1} \mathbf{x}_{\mathbf{j}} \text { for } i=j \\
\left(\hat{\mathbf{x}}_{\mathbf{j}}+\sum_{h \neq j} \hat{\mathbf{e}}_{\mathbf{h j}}\right)^{-1} \hat{\mathbf{e}}_{\mathbf{i j}} \text { for } i \neq j
\end{array}\right.
$$

where $\mathbf{e}_{\mathbf{i j}}$ is the vector of exports from region $i$ to region $j$. These proportions are also used to distribute transport services among the regional providers:

$$
\mathrm{T}_{\mathbf{S j}}=\sum_{\mathbf{i} \neq \mathbf{j}} \mathrm{T}_{\mathbf{i j}} \hat{\mathrm{S}}_{\mathbf{i j}}
$$

These are the block diagonal sub-matrices that comprise $\mathbf{T}_{\mathbf{S}}$, and the matrix $\mathbf{S}_{\mathbf{B}} \mathbf{T}_{\mathbf{S}} \mathbf{A}$ adds the provision of interregional transport to $\mathbf{A}_{\mathbf{B}}$.

The $\mathbf{S}_{\mathbf{B}}$ and $\mathbf{T}_{\mathbf{S}}$ matrices are also used to derive the production in a region of consumer goods and their domestic consumption or destination as exports to other regions, $\mathbf{Y}_{\mathbf{B}}$ (see the text for further details):

$$
\mathbf{Y}_{\mathbf{B}}=\mathbf{S}_{\mathbf{B}}\left(\mathbf{I}+\mathbf{T}_{\mathbf{S}}\right) \hat{\mathbf{y}}
$$

The $m n \times 1$ vector $\mathbf{Y}_{\mathbf{B}}$ is comprised of the row-sums of $\mathbf{Y}_{\mathbf{B}}$. Its entries for a particular region quantify the final goods that are produced in that region regardless of where they are ultimately consumed.

$$
\mathbf{y}_{\mathbf{B}}=\mathbf{S}_{\mathbf{B}}\left(\mathbf{I}+\mathbf{T}_{\mathbf{S}}\right) \mathbf{y}
$$


Next, we define $\mathbf{Y}_{\mathbf{O D}}$, the matrix containing the off-diagonal elements of $\mathbf{Y}_{\mathbf{B}}$ and zeroes down the diagonal. Its non-zero elements represent only those final goods that are traded among regions.

\subsection{Appendix 4. The Consumer-to-Factor Matrices for the scenarios in Section 4}

The numerical values for the Consumer-to-Factor matrices, $\boldsymbol{\Phi}_{\mathbf{B}}$, are given below for each of the scenarios: S0, S1, S2, and S3. The largest shifts are experienced in the second to last row, corresponding to receipts including scarcity rents by those with property rights to resources in region 3 . See the text for a discussion of these results.

S0:

$$
\boldsymbol{\Phi}_{\mathbf{B}}=\left(\begin{array}{cccc|cccc|cccc}
0.037 & 0.301 & 0.148 & 0.257 & 0.034 & 0.299 & 0.146 & 0.257 & 0.038 & 0.298 & 0.14 & 0.257 \\
0 & 0 & 0 & 0 & 0 & 0 & 0 & 0 & 0 & 0 & 0 & 0 \\
0 & 0 & 0 & 0 & 0 & 0 & 0 & 0 & 0 & 0 & 0 & 0 \\
\hline 0.289 & 0.118 & 0.055 & 0.072 & 0.293 & 0.117 & 0.055 & 0.072 & 0.288 & 0.116 & 0.054 & 0.072 \\
0 & 0 & 0 & 0 & 0 & 0 & 0 & 0 & 0 & 0 & 0 & 0 \\
0.578 & 0.236 & 0.111 & 0.143 & 0.585 & 0.233 & 0.11 & 0.143 & 0.577 & 0.231 & 0.109 & 0.143 \\
\hline 0.007 & 0.027 & 0.053 & 0.041 & 0.007 & 0.027 & 0.053 & 0.041 & 0.007 & 0.027 & 0.054 & 0.041 \\
0.088 & 0.318 & 0.633 & 0.488 & 0.082 & 0.324 & 0.635 & 0.488 & 0.09 & 0.327 & 0.644 & 0.488 \\
0 & 0 & 0 & 0 & 0 & 0 & 0 & 0 & 0 & 0 & 0 & 0
\end{array}\right)
$$

S1:

$\boldsymbol{\Phi}_{\mathrm{B}}=\left(\begin{array}{cccc|cccc|cccc}0.036 & 0.269 & 0.122 & 0.218 & 0.033 & 0.267 & 0.118 & 0.218 & 0.037 & 0.266 & 0.112 & 0.218 \\ 0.001 & 0.008 & 0.014 & 0.011 & 0.001 & 0.008 & 0.004 & 0.011 & 0.001 & 0.008 & 0.003 & 0.011 \\ 0 & 0 & 0 & 0 & 0 & 0 & 0 & 0 & 0 & 0 & 0 & 0 \\ \hline 0.279 & 0.105 & 0.044 & 0.06 & 0.283 & 0.103 & 0.044 & 0.06 & 0.278 & 0.102 & 0.043 & 0.06 \\ 0 & 0 & 0 & 0 & 0 & 0 & 0 & 0 & 0 & 0 & 0 & 0 \\ 0.559 & 0.21 & 0.089 & 0.12 & 0.567 & 0.206 & 0.088 & 0.12 & 0.557 & 0.205 & 0.086 & 0.12 \\ \hline 0.007 & 0.023 & 0.041 & 0.033 & 0.007 & 0.023 & 0.042 & 0.033 & 0.007 & 0.024 & 0.042 & 0.033 \\ 0.118 & 0.387 & 0.692 & 0.559 & 0.11 & 0.393 & 0.705 & 0.559 & 0.12 & 0.396 & 0.713 & 0.559 \\ 0 & 0 & 0 & 0 & 0 & 0 & 0 & 0 & 0 & 0 & 0 & 0\end{array}\right)$

S2:

$\boldsymbol{\Phi}_{\mathbf{B}}=\left(\begin{array}{cccc|cccc|cccc}0.037 & 0.272 & 0.127 & 0.223 & 0.033 & 0.27 & 0.119 & 0.223 & 0.037 & 0.269 & 0.113 & 0.223 \\ 0.003 & 0.02 & 0.038 & 0.03 & 0.003 & 0.021 & 0.01 & 0.03 & 0.003 & 0.021 & 0.009 & 0.03 \\ 0 & 0 & 0 & 0 & 0 & 0 & 0 & 0 & 0 & 0 & 0 & 0 \\ \hline 0.279 & 0.105 & 0.044 & 0.06 & 0.283 & 0.103 & 0.044 & 0.06 & 0.278 & 0.102 & 0.043 & 0.06 \\ 0 & 0 & 0 & 0 & 0 & 0 & 0 & 0 & 0 & 0 & 0 & 0 \\ 0.559 & 0.21 & 0.089 & 0.12 & 0.567 & 0.207 & 0.088 & 0.12 & 0.557 & 0.205 & 0.086 & 0.12 \\ \hline 0.007 & 0.022 & 0.04 & 0.032 & 0.006 & 0.023 & 0.042 & 0.032 & 0.007 & 0.023 & 0.042 & 0.032 \\ 0.116 & 0.373 & 0.666 & 0.538 & 0.108 & 0.379 & 0.698 & 0.538 & 0.118 & 0.382 & 0.707 & 0.538 \\ 0 & 0 & 0 & 0 & 0 & 0 & 0 & 0 & 0 & 0 & 0 & 0\end{array}\right)$

S3:

$$
\boldsymbol{\Phi}_{\mathbf{B}}=\left(\begin{array}{cccc|cccc|cccc}
0.027 & 0.124 & 0.041 & 0.082 & 0.025 & 0.128 & 0.04 & 0.082 & 0.028 & 0.121 & 0.036 & 0.082 \\
0.013 & 0.051 & 0.067 & 0.062 & 0.011 & 0.054 & 0.018 & 0.062 & 0.013 & 0.052 & 0.015 & 0.062 \\
0 & 0 & 0 & 0 & 0 & 0 & 0 & 0 & 0 & 0 & 0 & 0 \\
\hline 0.206 & 0.048 & 0.014 & 0.022 & 0.213 & 0.049 & 0.016 & 0.022 & 0.204 & 0.046 & 0.014 & 0.022 \\
0.01 & 0.002 & 0.001 & 0.001 & 0.01 & 0.002 & 0.036 & 0.001 & 0.01 & 0.002 & 0.001 & 0.001 \\
0.41 & 0.096 & 0.028 & 0.044 & 0.424 & 0.097 & 0.029 & 0.044 & 0.407 & 0.092 & 0.027 & 0.044 \\
\hline 0.005 & 0.01 & 0.012 & 0.011 & 0.005 & 0.01 & 0.013 & 0.011 & 0.005 & 0.01 & 0.013 & 0.011 \\
0.329 & 0.67 & 0.837 & 0.779 & 0.312 & 0.705 & 0.849 & 0.779 & 0.333 & 0.677 & 0.894 & 0.779 \\
0 & 0 & 0 & 0 & 0 & 0 & 0 & 0 & 0 & 0 & 0 & 0
\end{array}\right)
$$


Competing interests

The authors declare that they have no competing interests.

Received: 3 February 2015 Accepted: 28 May 2015

Published online: 10 July 2015

References

Dedrick J, Kraemer KL, Linden G (2010) Who profits from innovation in global value chains? A study of the iPod and notebook PCs. Industrial and Corporate Change 19(1):81-116

Dietzenbacher E, Los B, Stehrer R, Timmer MP, de Vries G (2013) The construction of world input-output tables in the WIOD project. Economic Systems Research 25(1):71-98

Duchin F, Levine SH, Strømman A (2015) Sustainable use of global resources: combining multiregional input-output analysis with a world trade model for analyzing scenarios. Part 1: conceptual framework. Journal of Industrial Ecology

Duchin F, Levine SH (2015) Sustainable use of global resources: combining multiregional input-output analysis with a world trade model for analyzing scenarios. Part 2: implementation. Journal of Industrial Ecology

Gereffi G, Korzeniewicz M (1994) editors. Commodity chains and global capitalism. Praeger, Westport, CT

Gereffi G, Lee J (2012) Why the world suddenly cares about global supply chains. Journal of Supply Chain Management 8(3):24-32

Graedel TE, Harper EM, Nassar NT, Reck BK (2013) On the materials basis of modern society. Proceedings of the National Academy of Sciences of the United States of America doi:10.1073/pnas.131275211.

Humphrey J, Memedovic O (2006) Global value chains in the agrifood sector. United Nations Industrial Development Organization Working Paper, Vienna, (http://www.unido.org/fileadmin/user_media/Publications/Pub_free/ Global_value_chains_in_the_agrifood_sector.pdf). Accessed June 9, 2015

Kaplinsky R, Morris M (2001) A handbook for value chain research. Prepared for the International Development Research Council (IDRC), University of Notre Dame, Notre Dame, Indiana

Palpacuer F, Gibbon P, Thomsen L (2005) New challenges for developing country suppliers in global clothing chains: a comparative European perspective. World Development. 33(3):409-30

Porter ME (1985) Competitive advantage. The Free Press, New York

Strømman AH, Duchin F (2006) A world trade model with bilateral trade based on comparative advantage. Economic Systems Research 18(3):281-97

Timmer MP, Erumban AA, Los B, Stehrer R, de Vries G (2014) Slicing up global value chains. Journal of Economic Perspectives 28(2):99-118

\section{Submit your manuscript to a SpringerOpen ${ }^{0}$ journal and benefit from:}

- Convenient online submission

- Rigorous peer review

- Immediate publication on acceptance

- Open access: articles freely available online

- High visibility within the field

- Retaining the copyright to your article

Submit your next manuscript at $>$ springeropen.com 